\title{
LETTERS
}

Send your letters to the editor, British Dental

Journal, 64 Wimpole Street, London W1G 8YS

E-mail bdj@bda.org

Priority will be given to letters less than 500

words long. Authors must sign the letter,

which may be edited for reasons of space

\section{Specialist dental training}

Sir, I have written the following as my response to the General Dental Council's recent request for views on entry to specialist dental training in the UK but wished also to share them with $B D J$ readers, as I feel so strongly.

The current entry requirements for dental specialist training in the UK are deeply damaging to patient care and morale in the dental profession. They demotivate many worthwhile candidates, depress standards of patient care in the UK National Health Service and deprive specialist practices of essential manpower. They are heavily biased against the practical intelligent individual and select mainly those who are fit only for the protected environments of hospital or academia having fled there after at most six months of unhappy general dental practice. They also discriminate against the mature entrant and exclude at least 90\% of the profession through their inability to pass the intellectual mountain of the Membership of Faculty of Dental Surgery (formerly Fellowship in Dental Surgery) or afford years out from NHS care. They force individuals to receive 10 or more years 'training', The current system delivers poor financial value; candidates are forced to fund three duplicate qualifications from universities and Royal Colleges of Surgeons where one would suffice.

Specialist practice in the UK needs individuals who actually want to treat patients as people and who are equipped to do so. It is over-supplied with researchers, academics and others who are essentially refugees from the tough realities of professional practice under selfemployment. The successful specialist understands not only their discipline but the needs and difficulties of those who refer patients to them. They need superlative communication skills and firstclass people-management skills.

The entry requirement should be that someone can demonstrate, through a simple log book of pictures, how their patients have benefited from the practitioner serving at least three years within a worthwhile general dental practice (not hospital or community). There they will have demonstrably coped with patient care, especially the provision of molar endodontics, crown and bridgework together with denture work ie the treatments that currently attract the highest level of negligence or indemnity settlement. This period allows them to handle the outcome of their decisions. During that period they will have had attachment(s) to specialist practices of say a day each week. This would allow them to test the waters without fear. It also avoids the 'watching Nellie' phenomenon because they experience real learning from people properly trained to enthuse and encourage rather than nit pick. The Royal Colleges of Surgeons should have no role in the entry requirements.

The current minimum lengths of training programmes need to be at most three years with a year of that droppable for those whose project demonstrates achievement. Remember that the individuals completing them have already had at least five years of undergraduate training and are prone to 'burn-out'. Using recognition of previous training towards the specialist training programme, in all specialties previous projects from general dental practice should attract at least a one year reduction in the overall training programme.

\section{Hogg \\ London}

doi: 10.1038/sj.bdj.4812607

\section{Blood borne viruses}

Sir, I recently received a circular from the Director of the Health Protection Agency concerning the management of patients with blood borne viruses. I completely accept its recommendations that we as dentists are ethically and legally obliged to treat patients who disclose that they have a blood borne virus. The circular

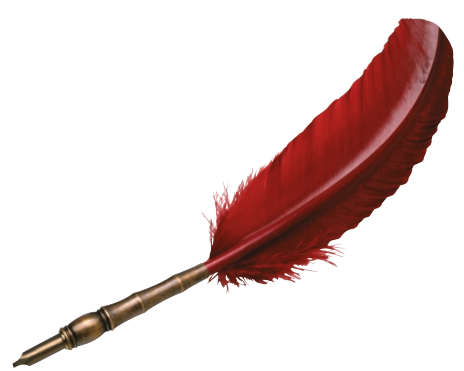

also advises that the policy of treating high risk patients at the 'end of a session' or 'the end of the day' should be ceased as this is a form of discrimination. It also states that all patients have the right to be treated with dignity, equality and respect. I wonder then if the same level of dignity, equality and respect would be extended to a dentist who became infected with a blood borne virus (eg hepatitis C)? The dentist would be legally obliged to inform the GDC, who would subsequently advise the dentist to cease practice. The dentist's life and career would be in ruins. Is this ethical and fair when we are obliged to treat patients with blood borne viruses and consequently risk our careers from an inadvertent needle stick injury? Universal precautions should be adhered to at all times and with all patients but the threat of a career ending needle stick injury shall always remain.

P. Tweddell

Ashford doi: 10.1038/sj.bdj.4812608

\section{British Dentist Association?}

Sir, the idea expressed in John Craig's

Presidential address, that the British

Dental Association should seek to become truly a dental association and not simply a dentist's association, has merit in today's team environment. Some formal process should be put in action to consider how to take this forward. Recent annual conferences have had the presence of PCD professional organisations. But I understand John's idea to be more than meeting alongside each other - so just how do we include the other dental team members in our association? If we look at the concerns of the BDA's founders that John mentions: 'standards of education and practice, maintenance of a register and the development of a profession based upon sound science and ethics', we find that this does not exclude others who practise some aspect of dentistry. We have already achieved something in this 
direction with the existing and forthcoming registers of PCDs with the GDC. But challenges abound in developing further the tentative initiatives in CPD provision for PCDs, both individually and as part of teams. Also in providing training and mentoring to involve PCDs more fully in clinical audit, further supporting high standards of practice. A more substantial imperative is to provide insight, motivation, training and leadership to involve PCDs in research in practice - so increasing the scientific basis for our practice of dentistry. Are there any others out there with ideas on how to proceed?

Y. Maidment

\section{By email}

doi: 10.1038/sj.bdj.4812609

\section{Maxillofacial toolkit}

Sir, we recently devised a novel use for an outdoor pursuits carry-case, ${ }^{1}$ which we thought would be of interest to your readers. As a Senior House Officer in Oral and Maxillofacial Surgery, often cross-covering another specialty (Ear, Nose and Throat Surgery) and working across several sites (Accident and Emergency Department, various wards), the problem arose where equipment to deal with patients on referral was difficult to obtain. As a solution to this problem and to ensure that such vital equipment was on hand and readily accessible as required, a portable, compact, multipurpose, weatherproof toolkit was devised.

The outdoor pursuits case is $150 \mathrm{~mm}$ (length) x IOO mm (width) x $30 \mathrm{~mm}$ (depth), with a 'slip-through' belt attachment and two shoulder strap attachments for alternative carrying and there is also a robust fabric covering. In addition, there is a key holder (could hold an on-call room key) and an outer smaller pocket, in which either a pager or mobile telephone could be carried. See photographs of case being worn and with contents.

This was, therefore, thought to be the ideal design to safely and conveniently transport the following equipment, most of which is effectively 'flat-pack' due to sterile packaging: four wooden spatulas, four alcohol wipes, three plastic bags for used equipment, one metal local anaesthetic syringe, three syringe needles of various lengths, three local anaesthetic cartridges (various types), one medium sized Maglite torch, 2 x 3/0 resorbable sutures, 2 x 5/0 nylon sutures, two small packets of Surgicel, one dental mirror, one disposable scalpel, one pair of college tweezers, one flat plastic instrument, one small container of temporary filling material, one small container of self-cure material, several short lengths of orthodontic wire, three cotton wool rolls, and from an ENT point of view: two Merocel nasal packs, two silver nitrate sticks and one Rapidrhino inflatable nasal balloon (all for epistaxis). This tightly packed comprehensive toolkit, which can be periodically and easily replenished during the working day, covers almost all of the on-call eventualities of the busy Maxillofacial SHO where equipment is needed and often expeditiously and can be used in conjunction with what is available on-site. (See photograph of some of the contents of the toolkit.)

We are aware that domiciliary kits for home dental care have been available for some time, but these tend to be large and heavy to carry, so are not suited to being carried on-person to several different locations. It would also appear from a search of the literature that such a compact and multiuse toolkit for this purpose has not been previously described.

\section{R. M. Graham}

\section{S. Salam}

\section{Manchester}

1. Purchased from an outdoor pursuits retailer for $€ 9.99$.

doi: 10.1038/sj.bdj.4812610
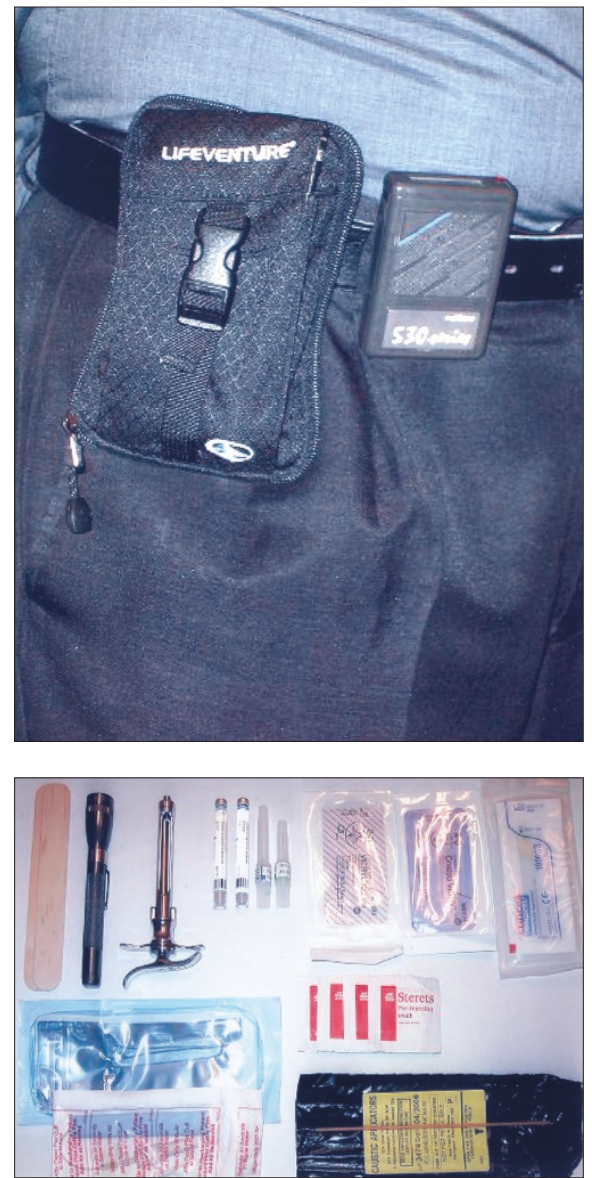